Check for updates

Cite this: Chem. Sci., 2019, 10, 2048

๑ All publication charges for this article have been paid for by the Royal Society of Chemistry

Received 9th October 2018

Accepted 10th December 2018

DOI: $10.1039 / c 8 s c 04489 a$

rsc.li/chemical-science

\section{A nonaqueous potassium-ion hybrid capacitor enabled by two-dimensional diffusion pathways of dipotassium terephthalate $\uparrow$}

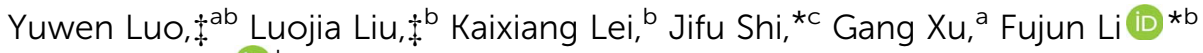 \\ and Jun Chen iD b
}

\begin{abstract}
Nonaqueous potassium-ion hybrid capacitors (KIHCs) are faced with limited redox reaction kinetics of electrodes for accommodation of large-sized $\mathrm{K}^{+}$. Here, dipotassium terephthalate $\left(\mathrm{K}_{2} \mathrm{TP}\right)$ is applied as an organic negative electrode to provide comparable reaction kinetics with a non-faradaic activated carbon (AC) positive electrode to boost the electrochemical performance of KIHCs. It is revealed that the large exchange current density and fast two-dimensional (2D) diffusion pathways of $\mathrm{K}^{+}$in $\mathrm{K}_{2} \mathrm{TP}$ determined by density functional theory (DFT) calculations ensure its fast redox reaction and transport kinetics. The asconstructed KIHC presents both high energy and power densities of $101 \mathrm{~W} \mathrm{~h} \mathrm{~kg}^{-1}$ and $2160 \mathrm{~W} \mathrm{~kg}^{-1}$ based on the mass of the two electrodes ( $41.5 \mathrm{~W} \mathrm{~h} \mathrm{~kg}^{-1}$ and $885.2 \mathrm{~W} \mathrm{~kg}^{-1}$ based on the mass of the two electrodes and electrolyte), respectively, and a superior capacity retention of $97.7 \%$ after 500 cycles. The excellent electrochemical performance is attributed to the fast kinetics, good structural flexibility, and small volume change (9.4\%) of $\mathrm{K}_{2} \mathrm{TP}$ upon $\mathrm{K}^{+}$insertion/extraction, and its good compatibility with the AC positive electrode in 1,2-dimethoxyethane (DME)-based electrolyte. This will promote application of organic materials in hybrid capacitors and the development of KIHCs.
\end{abstract}

\section{Introduction}

Nonaqueous hybrid capacitors have recently attracted extensive research interest, and are generally composed of battery-type negative electrodes and electric double-layer capacitor (EDLC)type positive electrodes. ${ }^{\mathbf{1 , 2}}$ They are endowed with the advantages of both high energy density of batteries and high power density and long lifespan of EDLCs. ${ }^{3-6}$ The equilibrium potential of $\mathrm{K}^{+} / \mathrm{K}$ is $-2.88 \mathrm{~V}$ in propylene carbonate (PC), which is lower than that of $\mathrm{Li}^{+} / \mathrm{Li}(-2.79 \mathrm{~V})$ or $\mathrm{Na}^{+} / \mathrm{Na}(-2.56 \mathrm{~V})$, providing wider operating voltage windows; $;^{7} \mathrm{~K}^{+}$has a smaller Stokes' radius $(3.6 \AA)$ than those of $\mathrm{Li}^{+}$and $\mathrm{Na}^{+}$in PC (4.8 and $4.6 \AA)$ due to its weaker Lewis acidity, suggesting its high mobility, that is, high ionic conductivity of $\mathrm{K}^{+}$in electrolytes. ${ }^{\mathbf{8}}$ The abundance of $\mathrm{K}$ resources in the Earth's crust is comparable to that of their $\mathrm{Na}$ counterparts and about three orders of magnitude higher than that of their Li counterparts, endowing

\footnotetext{
${ }^{a}$ Guangzhou Institute of Energy Conversion, Chinese Academy of Sciences, Guangzhou 510640, China

${ }^{b}$ Key Laboratory of Advanced Energy Materials Chemistry (Ministry of Education), College of Chemistry, Nankai University, Tianjin 300071, China. E-mail: fujunli@ nankai.edu.cn

'Siyuan Laboratory, Department of Physics, Jinan University, Guangzhou 510632, China.E-mail: shijifu2017@126.com

$\dagger$ Electronic supplementary information (ESI) available. See DOI: 10.1039/c8sc04489a

\$ These authors contributed equally.
}

it with potentially low cost and sustainability. ${ }^{\mathbf{9 1 0}}$ Therefore, developing nonaqueous potassium-ion hybrid capacitors (KIHCs) is highly desirable. However, KIHCs are plagued by poor kinetics of redox reactions and diffusion of large-sized $\mathrm{K}^{+}$ in the bulky electrode materials, which are usually much slower than the non-faradaic capacitive sorption of ions in EDLCs, and construction of KIHCs is faced with a materials challenge.

Carbon-based materials are attractive negative electrode candidates for $\mathrm{K}^{+}$storage, but their low redox potentials and rate capability preclude their usage in KIHCs. ${ }^{\mathbf{5 , 6 , 1 1 - 1 4}}$ Alloys and conversion-reaction-type negative electrode materials exhibit high capacity, but their large volume change during charge and discharge induce decaying performance. ${ }^{\mathbf{1 5}-19}$ Organic materials with structural flexibility enable fast $\mathrm{K}^{+}$diffusion and redox response, and have been attempted in potassium-ion batteries (KIBs). ${ }^{20-24}$ Chen et al. demonstrated the feasibility of 3,4,9,10perylene-tetracarboxylic acid-dianhydride for $\mathrm{K}^{+}$storage. $^{20}$ However, its capacity retention is only $66.1 \%$ after 200 cycles, which is attributed to its dissolution in electrolytes. Li's group has revealed that organic carboxyls are stable in electrolytes, and their redox potentials are between 0.5 and $1.0 \mathrm{~V} v s$. $\mathrm{K}^{+} / \mathrm{K}$, far from the deposition potential of $\mathrm{K}^{25}$ This can effectively circumvent the formation of $\mathrm{K}$ dendrites, and thus will promote safety, especially in high-rate devices. However, although they have been explored in Li-ion and Na-ion batteries, ${ }^{26,27}$ organic materials for KIHCs and the correlation of their molecular 
structures with kinetics of ions have never been reported, and are essential for construction of high-performance KIHCs.

Herein, we report a nonaqueous KIHC with an organic negative electrode of $\mathrm{K}_{2} \mathrm{TP}$, a positive electrode of AC and DMEbased electrolyte. $\mathrm{K}_{2} \mathrm{TP}$ is found to show fast $2 \mathrm{D}$ diffusion pathways for $\mathrm{K}^{+}$, structural flexibility, and a small volume change upon $\mathrm{K}^{+}$insertion/extraction by DFT calculations. The facile transport of $\mathrm{K}^{+}$in $\mathrm{K}_{2} \mathrm{TP}$ and its fast redox reaction kinetics are comparable to those of the non-faradaic AC positive electrode, and boost the electrochemical performance of the KIHC. Maximal power and energy densities of $2160 \mathrm{~W} \mathrm{~kg}^{-1}$ and $101 \mathrm{~W} \mathrm{~h} \mathrm{~kg}^{-1}$ are obtained, respectively, and it shows a high capacity retention of $97.7 \%$ after 500 cycles, which corresponds to a capacity loss of $0.0046 \%$ per cycle. Such excellent performance will encourage more investigations on organic materials in hybrid capacitors and promote the development of KIHCs.

\section{Results and discussion}

The KIHC was composed of a $\mathrm{K}_{2} \mathrm{TP}$ negative electrode, AC positive electrode, and DME-based electrolyte, as shown in Fig. 1a. The synthesis of $\mathrm{K}_{2} \mathrm{TP}$ is described in the ESI. $\dagger$ It is micrometers in size as displayed in the inset of Fig. 1b. The Xray diffraction (XRD) pattern of $\mathrm{K}_{2} \mathrm{TP}$ in Fig. $1 \mathrm{~b}$ is consistent with the standard JCPDS no. 52-2142, suggesting high purity. The Rietveld refinement fits well with the experimental data, and it is assigned to monoclinic $\mathrm{K}_{2} \mathrm{TP}$ with calculated cell parameters of $a=10.552 \AA, b=3.935 \AA, c=11.520 \AA, \beta=$ $113.08^{\circ}$, and $V=440.05 \AA^{3}$, as shown in Table $\mathrm{S} 1 . \dagger$ Fourier transform infrared (FTIR) spectroscopy results in Fig. $\mathrm{S} 1 \dagger$ further confirm the formation of $\mathrm{K}_{2} \mathrm{TP}$. AC features microporous bulky particles (see the inset), and shows a typical type I isotherm of $\mathrm{N}_{2}$ sorption (Fig. 1c). ${ }^{28}$ Its specific surface area is calculated to be $1699 \mathrm{~m}^{2} \mathrm{~g}^{-1}$ by the Brunauer-Emmett-Teller (BET) method, and its pore size is centered at $1.2 \mathrm{~nm}$ in Fig. $\mathrm{S} 2 \dagger$
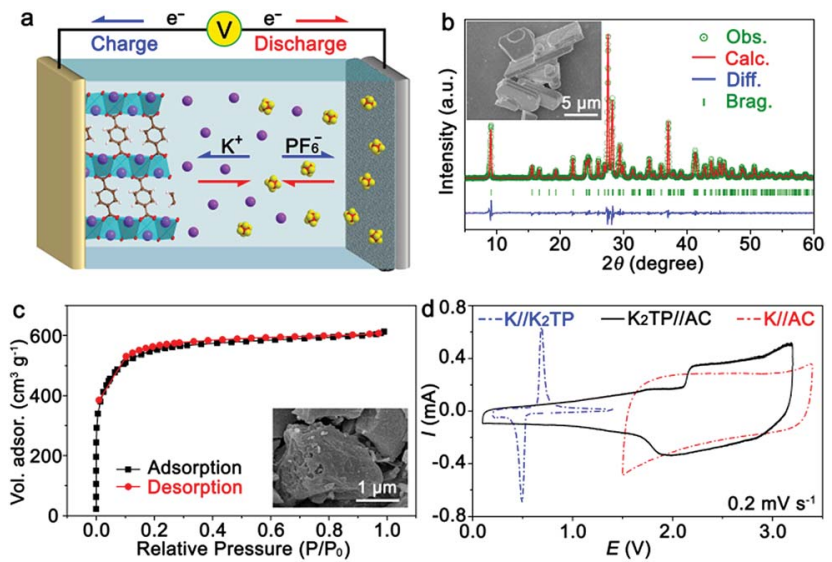

Fig. 1 (a) Schematic illustration of the KIHC with the configuration $K_{2} T P / / D M E-b a s e d$ electrolyte//AC; (b) XRD pattern, Rietveld-refined profile, and SEM image (inset) of $\mathrm{K}_{2} \mathrm{TP}$; (c) nitrogen sorption isotherm and SEM image (inset) of AC; and (d) CV curves of half batteries and the $\mathrm{KIHC}$. by Barrett-Joyner-Halenda analysis. The large surface area will favor reversible sorption of ions in KIHCs.

$\mathrm{K}_{2} \mathrm{TP}$ was first ball-milled with Super $\mathrm{P}$ in a ratio of $6: 3$ to promote electron conduction. It is $50-200 \mathrm{~nm}$ in size, as shown in the SEM image in Fig. S3. $\uparrow$ The as-prepared $\mathrm{K}_{2} \mathrm{TP}$ electrode presents a couple of redox peaks in the cyclic voltammetry (CV) curve in a half battery of $\mathrm{K} / / \mathrm{K}_{2} \mathrm{TP}$ at $0.2 \mathrm{mV} \mathrm{s}{ }^{-1}$, as shown in Fig. 1d. The discrepancy between the first and succeeding scans in Fig. S4a $\uparrow$ is attributed to the formation of a solid-electrolyte interphase (SEI). The redox peaks at $\sim 0.50$ and $0.67 \mathrm{~V}$ correspond to $\mathrm{K}^{+}$insertion/extraction. The discharge/charge profiles of $\mathrm{K}_{2} \mathrm{TP}$ are displayed in Fig. $\mathrm{S} 4 \mathrm{~b}$. $\dagger$ The representative plateaus are in agreement with the redox peaks in Fig. 1d. It shows good rate capability from 0.1 to $5 \mathrm{~A} \mathrm{~g}^{-1}$, and maintains a stable discharge/charge capacity of $220 \mathrm{~mA} \mathrm{~h} \mathrm{~g}^{-1}$ for 100 cycles with coulombic efficiencies of $\sim 100 \%$ beyond the initial cycles in Fig. S4c. $\uparrow$ These indicate high reversibility and rate capability of the $\mathrm{K}_{2} \mathrm{TP}$ electrode for $\mathrm{K}^{+}$storage.

According to the Randles-Sevcik equation (ESI $\dagger$ ), the peak currents are plotted against the square roots of scan rates of $\mathrm{CV}$ curves in Fig. S5. $\dagger$ The diffusion coefficient of $\mathrm{K}^{+}\left(\mathrm{D}_{\mathrm{K}^{+}}\right)$in $\mathrm{K}_{2} \mathrm{TP}$ is estimated to be $1.32 \times 10^{-11} \mathrm{~cm}^{2} \mathrm{~s}^{-1}$, which is three orders of magnitude larger than that of $\mathrm{Li}^{+}$in $\mathrm{LiFePO}_{4}\left(10^{-14} \mathrm{~cm}^{2} \mathrm{~s}^{-1}\right){ }^{29}$ Simultaneously, the exchange current density of $\mathrm{K}_{2} \mathrm{TP}$ can be derived from electrochemical impedance spectroscopy (EIS, Fig. S6 $\dagger)$ based on the equation $j_{0}=R T /\left(n A F R_{\mathrm{ct}}\right)$, where $j_{0}$ is the exchange current density, $R$ is the gas constant, $T$ is the temperature, $n$ is the charge-transfer number, $A$ is the contact area between the electrode and the electrolyte, $F$ is the Faraday constant, and $R_{\text {ct }}$ is the charge-transfer resistance. ${ }^{30}$ Accordingly, the exchange current density of $\mathrm{K}_{2} \mathrm{TP}$ is calculated to be $1.25 \times 10^{-3} \mathrm{~A} \mathrm{~cm}^{-2}$, which is superior to that of $\mathrm{LiFePO}_{4}(3.41 \times$ $\left.10^{-4} \mathrm{~A} \mathrm{~cm}^{-2}\right) .{ }^{29}$ All of this suggests facile kinetics of $\mathrm{K}^{+}$transport and redox reaction of $\mathrm{K}_{2} \mathrm{TP}$, which are consistent with its superior performance in half batteries.

On the other hand, the capacitive behavior of the AC positive electrode was evaluated in a half battery of $\mathrm{K} / \mathrm{AC}$ and the results are shown in Fig. 1d. It shows a typical CV curve with a rectangular shape, which is maintained at various scan rates, as shown in Fig. S7a $\uparrow$ and indicative of good capacitive performance. The charge/discharge profiles at different current densities in Fig. S7b $\uparrow$ exhibit triangular shapes, in good accordance with CV curves. A discharge capacity as high as $55.2 \mathrm{~mA} \mathrm{~h} \mathrm{~g}^{-1}$ is retained with a capacity retention of $\sim 100 \%$ after 100 cycles at $0.5 \mathrm{~A} \mathrm{~g}^{-1}$, as shown in Fig. S7c. $\dagger$ This is attributed to the large surface area and facile capacitive behavior of the microporous AC.

For the KIHC of $\mathrm{K}_{2} \mathrm{TP} / / \mathrm{AC}$, the mass ratio of $\mathrm{K}_{2} \mathrm{TP}$ to $\mathrm{AC}$ is optimized to be $1: 4$. The operating voltage window of the KIHC is determined to be $0.1-3.2 \mathrm{~V}$. Its CV curve in Fig. 1d exhibits combined behavior of redox reaction of $\mathrm{K}_{2} \mathrm{TP}$ and capacitive sorption of AC. In situ FTIR was applied to explore the reactions of $\mathrm{K}_{2} \mathrm{TP}$, which is based on its conjugated carboxyl groups, as illustrated in Fig. 2a. Each $\mathrm{K}_{2} \mathrm{TP}$ molecule accepts two $\mathrm{K}^{+}$, and the conjugated carboxyls are transformed into enolates $\left(\mathrm{K}_{4} \mathrm{TP}\right)$. The reversible transformation is monitored by in situ FTIR with a home-made cell in Fig. $2 \mathrm{~b}$, where the $\mathrm{K}_{2} \mathrm{TP}$ negative electrode 
a
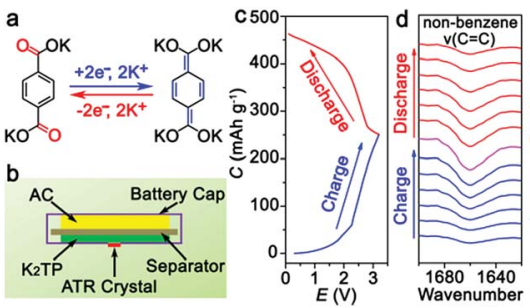

Fig. 2 (a) Redox reaction mechanism of $\mathrm{K}^{+}$with $\mathrm{K}_{2} \mathrm{TP}$; (b) diagram of a cell for in situ FTIR test; (c) charge/discharge profile of the KIHC at $20 \mathrm{~mA} \mathrm{~g}^{-1}$ (based on the mass of $\mathrm{K}_{2} \mathrm{TP}$ ); (d) in situ FTIR spectra of the $\mathrm{K}_{2}$ TP negative electrode in a charge/discharge cycle; and (e) Raman spectra of the $K_{2}$ TP negative electrode at selected states with copper powder.

is in close contact with an attenuated total reflection crystal of the spectrometer. As shown in Fig. 2c, the charge/discharge curve of the KIHC presents sloping plateaus. In the charging process, the intensity of the non-benzene $\mathrm{C}=\mathrm{C}$ vibration at $1660 \mathrm{~cm}^{-1}$ gradually increases, corresponding to potassiation of $\mathrm{K}_{2} \mathrm{TP}$, as shown in Fig. $2 \mathrm{~d}$. This is ascribed to the formation of $\mathrm{C}-\mathrm{O}$ bonds and conjugated non-benzene $\mathrm{C}=\mathrm{C}$ double bonds with weaker aromaticity, as shown in Fig. $2 \mathrm{a}$. In the subsequent discharging process, the peak intensity reversibly decreases due to depotassiation. This suggests reversible conversion of nonbenzene $\mathrm{C}=\mathrm{C}$ double bonds to $\mathrm{C}-\mathrm{C}$ bonds and formation of $\mathrm{C}=\mathrm{O}$ bonds. In addition, ex situ Raman spectra in Fig. 2e were also used to investigate the reaction process. In the fully charged state, a broad peak appears at $1516 \mathrm{~cm}^{-1}$, which is assigned to a combination of stretching vibrations of nonbenzene $\mathrm{C}=\mathrm{C}$ and $\mathrm{C}-\mathrm{O}$ bonds of $\mathrm{K}_{4} \mathrm{TP}$. This is in good accordance with the theoretically simulated Raman spectrum of $\mathrm{K}_{4} \mathrm{TP}$ in Fig. S8. $\dagger$ In the discharging process, the broad peak gradually decreases, and the characteristic peaks of $\mathrm{K}_{2} \mathrm{TP}$ appear as the simulated Raman spectrum of $\mathrm{K}_{2}$ TP in Fig. S9. $\dagger$ Both FTIR and Raman spectra clearly verify the electrochemical redox reaction of $\mathrm{K}_{2} \mathrm{TP}$ via the reversible transformation of conjugated carboxyls and enolates.

The crystal structures of $\mathrm{K}_{2} \mathrm{TP}$ and its fully potassiated $\mathrm{K}_{4} \mathrm{TP}$ are optimized by DFT calculations and depicted in Fig. 3. The

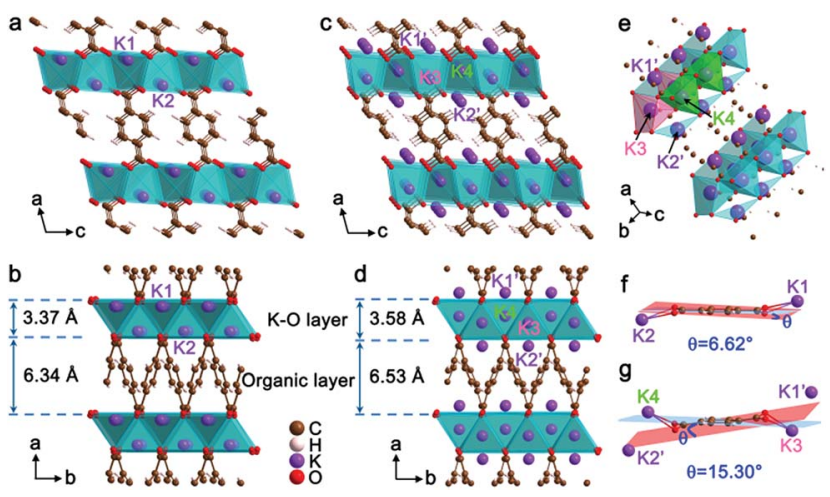

Fig. 3 Crystal structures of (a and b) $K_{2} T P$ and (c-e) $K_{4} T P$; and structural transformation of the terephthalate motif in (f) $K_{2} T P$ and $(g)$ $\mathrm{K}_{4} \mathrm{TP}$. The blue and red planes are defined by the carbon ring and carboxyl groups, respectively.

XRD pattern of $\mathrm{K}_{4} \mathrm{TP}$ in the discharge state agrees well with the simulated one in Fig. S10, $\dagger$ confirming the consistency of the crystal structure of $\mathrm{K}_{4} \mathrm{TP}$ with the experimental result. The structure of $\mathrm{K}_{2} \mathrm{TP}$ is shown in Fig. $3 \mathrm{a}$ and $\mathrm{b}$, where $\mathrm{K}-\mathrm{O}$ inorganic layers and $\pi$-stacking aromatic organic layers are alternatively arranged along the $a$ direction. In each $\mathrm{K}_{2} \mathrm{TP}$ molecule, the bond lengths of the adjacent $\mathrm{C}-\mathrm{O}$ bonds are 1.25 and $1.20 \AA$, respectively. The shorter $\mathrm{C}-\mathrm{O}$ bond is identified as carbonyl $(\mathrm{C}=\mathrm{O})$. The structure of $\mathrm{K}_{4} \mathrm{TP}$, with optimized cell parameters in Table S2, $\uparrow$ is displayed in Fig. 3c-e. The bond lengths of all $\mathrm{C}-\mathrm{O}$ bonds in each $\mathrm{K}_{4} \mathrm{TP}$ molecule are $1.35 \AA$ A. This is attributed to the disappearance of $\mathrm{C}=\mathrm{O}$ and formation of enolate. The two original $\mathrm{K}^{+}$of $\mathrm{K}_{2} \mathrm{TP}$ are marked $\mathrm{K} 1$ and $\mathrm{K} 2$, and the two inserted $\mathrm{K}^{+}$are marked $\mathrm{K} 3$ and $\mathrm{K} 4$, which push $\mathrm{K} 1$ and $\mathrm{K} 2$ into the $\mathrm{K} 1^{\prime}$ and $\mathrm{K}^{\prime}$ sites during potassiation. Meanwhile, the coordination of $\mathrm{K}^{\prime}{ }^{\prime}$ and $\mathrm{K}^{\prime}{ }^{\prime}$ with $\mathrm{O}$ is changed into $\mathrm{KO}_{4}$ coordination from $\mathrm{KO}_{6}$. The thickness of the $\mathrm{K}-\mathrm{O}$ layer and organic layer increases by $6.2 \%$ and $3.0 \%$, respectively, and then the volume expansion is only $9.4 \%$. When comparing the terephthalate motifs between $\mathrm{K}_{2} \mathrm{TP}$ and $\mathrm{K}_{4} \mathrm{TP}$, a distinct structural distortion can be observed in Fig. $3 \mathrm{f}$ and g. In $\mathrm{K}_{2} \mathrm{TP}$, the dihedral angle between the planes of carboxyl groups and the carbon ring is $6.62^{\circ}$, as shown in Fig. 3f, while it increases to $15.30^{\circ}$ in $\mathrm{K}_{4} \mathrm{TP}$ in Fig. $3 \mathrm{~g}$. This indicates good structural flexibility of the terephthalate motif, which facilitates diffusion of $\mathrm{K}^{+}$. Of note, the volume expansion of $\mathrm{K}_{2} \mathrm{TP}$ after potassiation is significantly smaller than for the negative electrode materials reported so far, for instance, $61 \%$ for graphite ${ }^{31}$ and $409 \%$ for $\mathrm{Bi}^{32}$ The small volume change and high structural flexibility of $\mathrm{K}_{2} \mathrm{TP}$ favor the diffusion and storage of $\mathrm{K}^{+}$.

The charge evolution, apart from $\mathrm{K}^{+}$ions, in the reversible transformation of $\mathrm{K}_{2} \mathrm{TP}$ to $\mathrm{K}_{4} \mathrm{TP}$ is revealed by a Bader charge change on their carbon and oxygen atoms, as shown in Fig. S11 and Table S3. $\dagger$ The charge transfer mainly occurs on carbon atoms with an almost constant Bader charge on oxygen atoms after full potassiation. In particular, the carbon atoms in the carboxyl groups of $\mathrm{K}_{4} \mathrm{TP}$ are localized with a large amount of charge. This suggests that the carbon atoms of carboxyl groups are charge transfer centers rather than oxygen atoms. It is implicated that the $\pi$-stacking aromatic organic layer ensures electron conduction and the inorganic layer of $\mathrm{K}-\mathrm{O}$ polyhedrons linked through edge sharing is responsible for $\mathrm{K}^{+}$diffusion.

The diffusion pathways of $\mathrm{K}^{+}$in the optimized crystal structure of $\mathrm{K}_{4} \mathrm{TP}$, based on dispersion-corrected density functional theory (DFT-D2) ${ }^{33}$ are depicted by molecular dynamics simulation at $2000 \mathrm{~K}$ in all the possible diffusion directions. The connected trajectories of $\mathrm{K}^{+}$during the $10 \mathrm{ps}$ (10 000 steps) simulation represent the migration pathways of $\mathrm{K}^{+}$, as shown in Fig. 4a and S12. $\dagger$ It is clear that $\mathrm{K}^{+}$migrates in the twodimensional ac plane. The diffusion pathways of $\mathrm{K}^{+}$were studied using the climbing-image nudged elastic band method to find the path with the minimum energy and barrier between certain diffusion starting and ending points. The diffusion was treated as a $\mathrm{K}^{+}$migrating from a stable position to the created $\mathrm{K}^{+}$ vacancy in $\mathrm{K}_{4} \mathrm{TP}$. Three different diffusion pathways of $\mathrm{K}^{+}$ were designed, denoted as path A $(4 \rightarrow 3 \rightarrow 5 \rightarrow 1 \rightarrow 0)$, path $\mathrm{B}$ $(4 \rightarrow 3 \rightarrow 2 \rightarrow 1 \rightarrow 0)$ and path $\mathrm{C}\left(1 \rightarrow 1^{\prime}\right)$ in Fig. $4 \mathrm{~b}$ and S13, $\dagger$ 

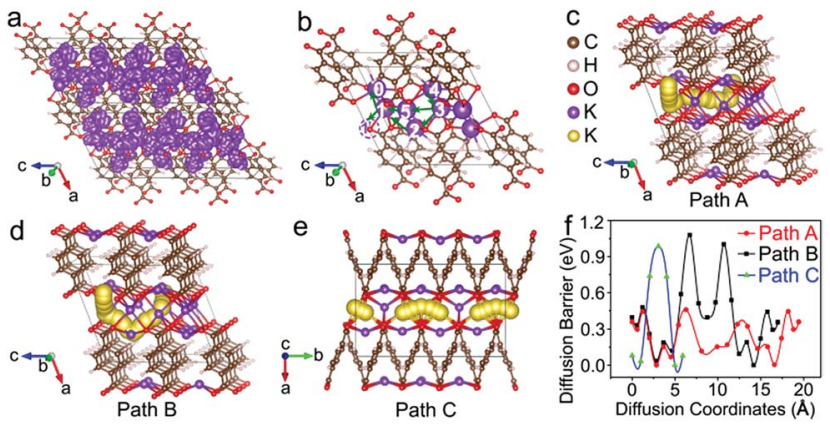

Fig. 4 (a) Trajectories of $\mathrm{K}^{+}$in $\mathrm{K}_{4} \mathrm{TP}$ obtained by $M D$ simulation at $2000 \mathrm{~K}$ for $10 \mathrm{ps}$; (b) designed $\mathrm{K}^{+}$diffusion path $\mathrm{A}(4 \rightarrow 3 \rightarrow 5 \rightarrow 1 \rightarrow 0$ ), $\mathrm{B}(4 \rightarrow 3 \rightarrow 2 \rightarrow 1 \rightarrow 0)$, and $\mathrm{C}\left(1 \rightarrow 1^{\prime}\right)$ in $\mathrm{K}_{4} \mathrm{TP}$; (c) path $\mathrm{A}$ of $\mathrm{K}^{+}$ diffusion; (d) path $\mathrm{B}$ of $\mathrm{K}^{+}$diffusion; (e) path $\mathrm{C}$ of $\mathrm{K}^{+}$diffusion; and (f) energy profiles of $\mathrm{K}^{+}$migration in path $\mathrm{A}, \mathrm{B}$ and $\mathrm{C} . \mathrm{K}^{+}$is displayed in different sizes and colors in (a-e) for clarity.

respectively. In path A of Fig. 4c, the diffusion barrier was calculated to be $0.46 \mathrm{eV}$, which is the minimum. Moreover, the diffusion barrier of $\mathrm{K}^{+}$migrating from position $1 \rightarrow 0$ and $4 \rightarrow 3$ was calculated to be as low as $0.08 \mathrm{eV}$, which favors facile migration between these positions. Path B in Fig. 4d and path $\mathrm{C}$ in Fig. 4e present higher diffusion barriers of 1.08 and $0.98 \mathrm{eV}$, respectively. The calculated energy profiles along the three pathways are comparatively shown in Fig. 4f. It is obvious that path A has overall low energy barriers and is the optimal diffusion pathway for $\mathrm{K}^{+}$. This guarantees outstanding ionic conductivity and contributes to the excellent electrochemical performance, especially high rate capability. According to an empirical estimation criterion, a migration barrier of $0.525 \mathrm{eV}$ corresponds to a typical ionic diffusivity of $10^{-12} \mathrm{~cm}^{2} \mathrm{~s}^{-1}$ at room temperature, and a $0.06 \mathrm{eV}$ increase/decrease in the migration energy leads to an order of magnitude decrease/ increase in the ionic diffusivity. ${ }^{34}$ Thus, the $0.46 \mathrm{eV}$ diffusion barrier results in a diffusion coefficient of $\sim 10^{-11} \mathrm{~cm}^{2} \mathrm{~s}^{-1}$, matching well with the experimental $\mathrm{D}_{\mathrm{K}^{+}}$in $\mathrm{K}_{2} \mathrm{TP}$ of $1.32 \times$ $10^{-11} \mathrm{~cm}^{2} \mathrm{~s}^{-1}$.

Capacitive adsorption/release of $\mathrm{PF}_{6}{ }^{-}$onto/from the surface of the AC positive electrode is investigated by elemental mapping. When the KIHC was fully charged, fluorine and phosphorus can be clearly detected as shown in Fig. S14a $\dagger$ with atomic ratios of $1.49 \%$ and $0.68 \%$ with respect to carbon, respectively, suggesting that $\mathrm{PF}_{6}{ }^{-}$is adsorbed on the AC surface from the electrolyte. After discharge, the atomic ratios of fluorine and phosphorus are dramatically decreased to $0.23 \%$ and $0.07 \%$, respectively, in Fig. $\mathrm{S} 14 \mathrm{~b}, \dagger$ indicating release of $\mathrm{PF}_{6}{ }^{-}$ from the AC surface into the electrolyte. The reversible charge storage stems from reversible adsorption and release of $\mathrm{PF}_{6}{ }^{-}$in EDLs of the AC positive electrode.

Fig. 5a presents the rate capability of the KIHC at different current densities. Capacities of 43.5, 41.3, 35.9, 32.1, 28.2, and $23.9 \mathrm{~mA} \mathrm{~h} \mathrm{~g}^{-1}$ are obtained at current densities of 20, 40, 100, 200, 400, and $1000 \mathrm{~mA} \mathrm{~g}^{-1}$, respectively. The selected charge/ discharge curves are depicted in Fig. 5b. The sloping plateaus are clearly observed in the charging/discharging process, and are in good agreement with CVs in Fig. 1d. The cycle life of the
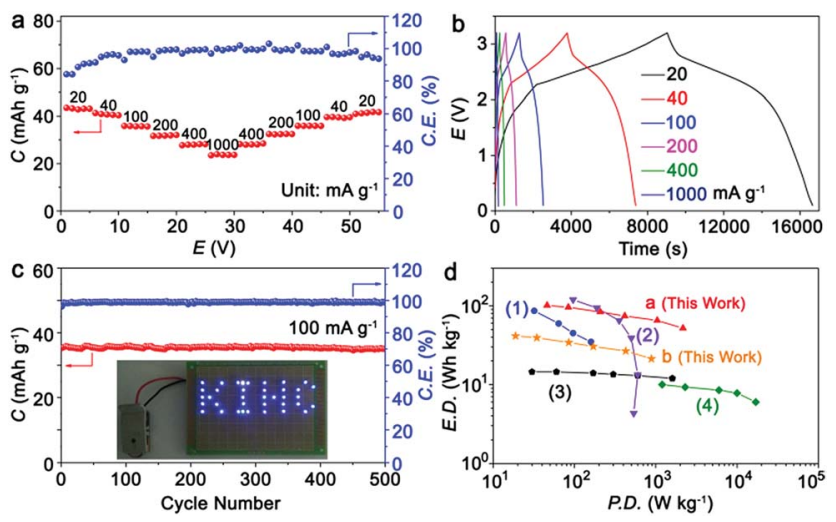

Fig. 5 (a) Rate capability; (b) charge/discharge curves at different rates; (c) cycling performance of the $\mathrm{KIHC}$ at $100 \mathrm{~mA} \mathrm{~g}^{-1}$ for 500 cycles; and (d) Ragone plots of the KIHC of $\mathrm{K}_{2} \mathrm{TP} / / \mathrm{AC}$, and other reported KIHCs, a KIB, and an EDLC. (1) Soft carbon// $\mathrm{K}_{0.7} \mathrm{Fe}_{0.5} \mathrm{Mn}_{0.5} \mathrm{O}_{2}$ (KIB), ref. 12; (2) soft carbon//AC (KIHC), ref. 6; (3) graphite//AC (KIHC), ref. 5; (4) AC//AC (EDLC), ref. 35. The current density, capacity, power density and energy density are all based on the total mass of active materials in both electrodes. Exceptionally, plot $b$ is based on the mass of both electrodes and the electrolyte.

KIHC is displayed in Fig. 5c. After 500 cycles, the capacity retention is $97.7 \%$ and the coulombic efficiencies are close to $100 \%$, implying superior cycling stability of the KIHC. The logo "KIHC" in a pattern of light-emitting diodes is powered by one single KIHC as shown in the inset of Fig. 5c, indicating its potential for application. The KIHC delivered a high energy density of $101 \mathrm{~W} \mathrm{~h} \mathrm{~kg}^{-1}$ at a power density of $46 \mathrm{~W} \mathrm{~kg}^{-1}$ based on the total mass of active materials in both electrodes, as shown in Fig. 5d. Remarkably, a moderate energy density of $52 \mathrm{~W} \mathrm{~h} \mathrm{~kg}{ }^{-1}$ can be achieved even at an exceptionally high power density of $2160 \mathrm{~W} \mathrm{~kg}^{-1}$, demonstrating a good balance between energy and power density. Its overall gravimetric performance is higher than that of many recently reported potassium-ion based capacitors and batteries, such as soft carbon $/ / \mathrm{K}_{0.7} \mathrm{Fe}_{0.5} \mathrm{Mn}_{0.5} \mathrm{O}_{2} \quad(\mathrm{KIB}),{ }^{12}$ soft carbon//AC (KIHC), ${ }^{6}$ graphite//AC (KIHC), ${ }^{5}$ and AC//AC (EDLC).${ }^{35}$ Besides, taking the electrolyte into account, the $\mathrm{KIHC}$ of $\mathrm{K}_{2} \mathrm{TP} / / \mathrm{AC}$ possesses a little lower energy density $\left(41.5 \mathrm{~W} \mathrm{~h} \mathrm{~kg}^{-1}\right)$ than $54 \mathrm{~W} \mathrm{~h} \mathrm{~kg}^{-1}$ of $\mathrm{Ni}-\mathrm{Cd}$ batteries but a much higher power density of $885.2 \mathrm{~W} \mathrm{~kg}^{-1} v s$. $125 \mathrm{~W} \mathrm{~kg}^{-1}$ of Ni-Cd batteries. ${ }^{36}$ This is due to the fast kinetics of capacitive behavior of the carbon electrode and redox reactions of $\mathrm{K}_{2} \mathrm{TP}$, and shows the advantage of hybrid capacitors.

\section{Conclusions}

In summary, a high-performance KIHC was successfully constructed using a $\mathrm{K}_{2} \mathrm{TP}$ organic negative electrode and AC positive electrode with DME-based electrolyte. It works with redox reaction of $\mathrm{K}_{2} \mathrm{TP}$ via reversible transformation of conjugated carboxyls and enolates and capacitive sorption of $\mathrm{PF}_{6}{ }^{-}$in EDLs of AC. DFT calculations indicate a small volume change of 9.4\% during discharge/charge of $\mathrm{K}_{2} \mathrm{TP}$, thanks to the flexibility of the terephthalate motifs. It is found that the $\pi$-stacking aromatic organic layer and the $\mathrm{K}-\mathrm{O}$ inorganic layer are responsible for 
electron conduction and $\mathrm{K}^{+}$diffusion, respectively. The $2 \mathrm{D}$ diffusion pathways of $\mathrm{K}^{+}$have the lowest diffusion barrier of $0.46 \mathrm{eV}$, and ensure facile $\mathrm{K}^{+}$diffusion to match with the nonfaradaic capacitive kinetics of the AC positive electrode. The KIHC demonstrates a high energy density of $101 \mathrm{~W} \mathrm{~h} \mathrm{~kg}^{-1}$, high power density of $2160 \mathrm{~W} \mathrm{~kg}^{-1}$ based on the mass of the two electrodes, and long lifetime with a capacity retention of $97.7 \%$ after 500 cycles. These are attributed to the fast kinetics and high exchange current density of the organic electrode of $\mathrm{K}_{2} \mathrm{TP}$ and its small volume change during discharge/charge. This investigation reveals promising applications of KIHCs for large scale electric energy storage, and will promote the development of organic functional materials.

\section{Conflicts of interest}

There are no conflicts to declare.

\section{Acknowledgements}

Financial support from the National Natural Science Foundation of China (21603108 and 21673243), the Fundamental Funds for the Central Universities, and the NSFC-RGC Joint Program (51761165025) is acknowledged.

\section{Notes and references}

1 N. Choudhary, C. Li, J. Moore, N. Nagaiah, L. Zhai, Y. Jung and J. Thomas, Adv. Mater., 2017, 29, 1605336.

2 P. Jeżowski, O. Crosnier, E. Deunf, P. Poizot, F. Béguin and T. Brousse, Nat. Mater., 2018, 17, 167.

3 L. Shen, H. Lv, S. Chen, P. Kopold, P. Aken, X. Wu, J. Maier and Y. Yu, Adv. Mater., 2017, 29, 1700142.

4 B. Yang, J. Chen, S. Lei, R. Guo, H. Li, S. Shi and X. Yan, Adv. Energy Mater., 2018, 8, 1702409.

5 A. Comte, Y. Reynier, C. Vincens, C. Leys and P. Azaïs, J. Power Sources, 2017, 363, 34.

6 L. Fan, K. Lin, J. Wang, R. Ma and B. Lu, Adv. Mater., 2018, 30, 1800804.

7 Y. Marcus, Pure Appl. Chem., 1985, 57, 1129.

8 Y. Matsuda, H. Nakashima, M. Morita and Y. Takasu, J. Electrochem. Soc., 1981, 128, 2552.

9 Q. Zhao, J. Wang, Y. Lu, Y. Li, G. Liang and J. Chen, Angew. Chem., Int. Ed., 2016, 55, 12528.

10 K. Beltrop, S. Beuker, A. Heckmann, M. Winter and T. Placke, Energy Environ. Sci., 2017, 10, 2090.

11 Z. Jian, W. Luo and X. Ji, J. Am. Chem. Soc., 2015, 137, 11566.

12 X. Wang, X. Xu, C. Niu, J. Meng, M. Huang, X. Liu, Z. Liu and L. Mai, Nano Lett., 2017, 17, 544.
13 C. Vaalma, G. Giffin, D. Buchholz and S. Passerini, J. Electrochem. Soc., 2016, 163, A1295.

14 Y. Xu, C. Zhang, M. Zhou, Q. Fu, C. Zhao, M. Wu and Y. Lei, Nat. Commun., 2018, 9, 1720.

15 I. Sultana, T. Ramireddy, M. M. Rahman, Y. Chen and A. M. Glushenkov, Chem. Commun., 2016, 52, 9279.

16 R. Zhang, J. Bao, Y. Wang and C. Sun, Chem. Sci., 2018, 9, 6193.

17 W. Zhang, J. Mao, S. Li, Z. Chen and Z. Guo, J. Am. Chem. Soc., 2017, 139, 3316.

18 Y. Lu and J. Chen, Sci. China: Chem., 2017, 60, 1533.

19 X. Ren, Q. Zhao, W. McCulloch and Y. Wu, Nano Res., 2017, 10, 1313.

20 Y. Chen, W. Luo, M. Carter, L. Zhou, J. Dai, K. Fu, S. Lacey, T. Li, J. Wan, X. Han, Y. Bao and L. Hu, Nano Energy, 2015, 18, 205.

21 Z. Jian, Y. Liang, I. Rodríguez-Pérez, Y. Yao and X. Ji, Electrochem. Commun., 2016, 71, 5.

22 J. Pramudita, D. Sehrawat, D. Goonetilleke and N. Sharma, Adv. Energy Mater., 2017, 7, 1602911.

23 Y. Liang, Y. Gheytani, K. Lee, P. Liu, A. Facchetti and Y. Yao, Nat. Mater., 2017, 16, 841.

24 Z. Song, Y. Qian, X. Liu, T. Zhang, Y. Zhu, H. Yu, M. Otani and H. Zhou, Energy Environ. Sci., 2014, 7, 4077.

25 K. Lei, F. Li, C. Mu, J. Wang, Q. Zhao, C. Chen and J. Chen, Energy Environ. Sci., 2017, 10, 552.

26 M. Armand, S. Grugeon, H. Vezin, S. Laruelle, P. Ribière, P. Poizot and J.-M. Tarascon, Nat. Mater., 2009, 8, 120.

27 A. Jouhara, N. Dupré, A.-C. Gaillot, D. Guyomard, F. Dolhem and P. Poizot, Nat. Commun., 2018, 9, 4401.

28 E. Raymundo-Piñero, K. Kierzek, J. Machnikowski and F. Béguin, Carbon, 2006, 44, 2498.

29 D. Li, T. Zhang, X. Liu, P. He, R. Peng, M. Wang, M. Han and H. Zhou, J. Power Sources, 2013, 233, 299.

30 H. Ma, S. Zhang, W. Ji, Z. Tao and J. Chen, J. Am. Chem. Soc., 2008, 130, 5361.

31 J. Yang, Z. Ju, Y. Jiang, Z. Xing, B. Xi, J. Feng and S. Xiong, Adv. Mater., 2018, 30, 1700104.

32 K. Lei, C. Wang, L. Liu, Y. Luo, C. Mu, F. Li and J. Chen, Angew. Chem., Int. Ed., 2018, 57, 46877.

33 S. Grimme, J. Comput. Chem., 2006, 27, 1787.

34 M. Liu, Z. Rong, R. Malik, P. Canepa, A. Jain, G. Ceder and K. A. Persson, Energy Environ. Sci., 2015, 8, 964.

35 D. Dubal, N. Chodankar, R. Holze, D. Kim and P. GomezRomero, ChemSusChem, 2017, 10, 1771.

36 G. P. Hammond and T. Hazeldine, Appl. Energy, 2015, 138, 559. 